\title{
KAZAK DÜNYA GÖRÜŞÜNDE "BAQIT" (MUTLULUK) KAVRAMI
}

\author{
Prof. Dr. Janalık BALTABAEVA* \\ A.A. BIYYAZDİKOVA**
}

ÖZ: Günümüzde dilbilimi alanında kavram yani "net veriler" etrafındaki yorumlamalar yaygınlık kazanmaktadır. Bu kavram, bir halk veya toplum çevresinde olup bitene "kendine özgü bir gözle bakma" veya bundan hareketle millîlik niteliğini taşıyan anlamlar etrafında yoğunlaşmaktadır.

Kaleme aldığımız kavrama konu olan deyimlerimiz "baht, mutluluk" ile ilgilidir. Bahtiyar olma, mutlu olma hemen hemen bütün millet ve topluluklarda farklı anlamlar taşımaktadır. Bir taraftan felsefe, psikoloji gibi bilim dalları ile bir taraftan da toplumbilim, insanbilim, yaş anatomisi gibi çeşitli bilim dalları ile ilgili bulunmaktadır.

Asıl amacımız, bu kelimeyi dilbilim açısından değerlendirmektir.

Anahtar Kelimeler: Kazak, halk kültürü, dünya görüşü, baht, bakıt, talih, talay

\section{The Concept of Happiness in Kazakh Understanding}

ABSTRACT: Nowadays the meaning of concept, which is considered as "clear findings/solid fiqures", forms the basis of evaluation. The concept of Baqit in relation to societal understanding with reference to the occurrences, is considered to be self evaluative and national meaning to happiness is also attached The main concept of this study is happiness. The meaning of happiness varies from society to society On the one hand, the concept is linked to scholarships such as philosophy, psychology, as well as sociolinguistics, anthropology, age anatomy as well.

\footnotetext{
* Abay Adındaki Millî Pedagoji Üni., Almatı/Kazakistan, baltabaeva2hanalik@1aail.ru

** Abay Adındaki Millı̂ Pedagoji Üni. doktora öğrencisi, Almatı/Kazakistan
} 
Key Words: cognitive linguistics, concept, the concept of "happiness", the Kazakh outlook, happiness

\section{GİRIŞ}

Günümüzde Kognetif dilbilminin temel terimlerinden biri haline gelen "konsept" (kavram) sözü geniş anlamıyla ele alınmaktadır. Çünkü dünyayı kognetif açıdan incelemede mezkûr kavram büyük önem arz etmektedir.

Deyimlerin ortaya çıkışı hakkında birçok dilbilimci görüş beyan etmiştir. Bu alanda ilk çalışma yapanlardan Rus bilim adamı V. A. Maslova, deyim ve onun incelenmesiyle ilgili olarak şunları dile getirmiştir:

"Her şeyden önce deyimler dilin kendisinde gizlidir. Ama tam olarak neresinde? Bazı dilbilimciler merkezi konseptleri (kavramları) dilbilgisinde kendisini yansıtacağını öne sürse de bazıları onların kelimelerde görüleceğini kabul ediyorlar” (Maslova 2004: 16).

Rus kognitoloji uzmanı S. G. Vorkaçev: "Dil kültürü bilimsel metinlerde deyim her şeyden önce kültürel bir kavramdır. Aynı zamanda $o$, dil kültürün semantik birimidir. $O$, çift yönlü dil işareti olarak hiçbir şeyle sinırlandırılmayacak şekilde oluşacaktır" diyerek "kavram"1n iki ayrı unsurunu belirtmiştir (Vorkaçev 2006: 2).

E. Orazaliyeva ise deyimi,

“.. insan şuurunun düşünme birimleri ile psikolojik kaynaklarını ve bilgi ile tecrübenin betimlenmiş göstergelerinden oluşan, algılanmış olguları açıklamaya imkân sağlayan kognetif dil biliminin temel araçlarından biridir"

şeklinde tanımlar (Orazaliyeva 2007: 266).

Bilim adamlarının zikrettikleri görüşlerinden hareketle deyimi, "Dünyayla ilgili idrak ve görüşlerin geniş çaplı anlam ifade eden karmaşık bir olgu." şeklinde tarif etmek mümkündür.

İnsanın kültürel düşünce ufku ne kadar darsa, onun dili, kelime hazînesinin deyimlerle ilgili düzeyi o kadar kıt olur. Deyim, kelimelerin anlamını değiştirmekle kalmaz, aynı zamanda kelime anlamını idrak etmede farklılıklar ile anlaşmazlığg giderir; böylece iletişimi kolaylaştırır; kelime anlamını genişleterek düşünmeyi devam ettirmeye, hayal etmeye ve kelimenin duygusal ruhunu genişletmeye imkân sağlar. Konsept, 
insanın kişisel tecrübesi sonucu oluşmaz. İnsanların hepsi aynı derecede millî dilin konseptolojik (kavramsal) düzeyini genişletmeye ve zenginleştirmeye kabiliyetli değildir. Bu yüzden de kavram oluşturmada halk edebiyatının çeşitli alanları (örneğin, atasözleri, deyimler, vecizeler, bilmece ve tekerlemeler vs.) ve bu alanların temsilcileri, şairler ile yazarların etkisi ve katkısı büyüktür.

İnsan kendi bilişsel davranışlarını dünyayı tanımaya yönelik bir geliştirici süreç olarak bilmeli ve ona göre ayarlamalıdır. Çünkü bu davranışlar nesnenin benzerlikleri ile farklılıklarım ayırt etmekle başlar. Bu davranışlar sonucu deyim oluşur.

Deyimi tespit edebilmek için hayatın bazı özellikleri ile maddî değerleri, onların nesnelerle münasebeti, fonksiyonlarıyla birlikte onlar üzerinde yapılmıș olan millî șuurun tasviri ve değerlendirmesi saptanmalıdır. Deyimle ilgili kavramın oluşabilmesi için bir millet tarafından kullanılmış olması, aynı zamanda o milletin asırlardır süregelen kültürü, medeniyeti, örfü, adetleri, dini ve diliyle doğrudan ilişkili bir şekilde kullanılarak belli bir kültürel seviyeye ulaşmaș şarttır.

\section{Hayatı Anlamlandırmada İki Anahtar: Bakıt ve Talay}

Millî kültürü, dini, örf ve adetleri ve diliyle iç içe kaynaşarak milletin millî varlığını yansıtan bilişsel anlam ifade eden kelimeler d' günümüz Kazakçasında çokça görülmektedir. Bunlardan biri "Baqıt" (mutluluk, baht) kavramıdır. Bu, herhangi bir ulusta mevcut olan evrensel soyut ve karmaşık bir kavramdır. Aynı zamanda "Baqıt" (baht, mutluluk) felsefe ve psikoloji gibi bilim dallarında da önde gelen kavramlardandır.

Kazakların dünya görüşlerinde, millî varlığı ile yaşam tarzlarında ve dünyayı tasvir etmelerinde mutluluk, önde gelen kavramlardan biridir. Mutluluk, milletin kavram olarak dünya görüşünü oluşturan önemli kategorilerdendir.

Pek çok filozof, "Mutluluk, her şeyden önce insanoğlunun nice kez

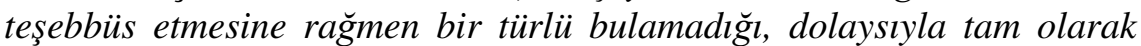
bilinemeyen bir bilişsel kavramdır", der (Bijanova 2010: 67).

Kazakların hayat anlayışında, hayatın anlamı, belli ölçüde mutluluğun ön şartıdır, aynı zamanda mutlu olmaya çabalama bile hayata belli anlam ve renk katmaktadır. Amaçsız bir biçimde yaşamak insan için gerçek anlamda mutsuzluktur. Aksine insan kendi yaşadığı hayatı derinlikleriyle kavrayabilirse mutluluğun ne olduğunu hissedebilir. Mutluluk kavramı yaratılışın istikrarlı ve değişken donanımı olmasının yanı sıra günlük hayatın da amaç ve yönlerini belirler. 
30

TÜBAR-XXXVI / 2014-Güz / J. BALTABAEVA-A.A. BİYAZDİKOVA

\section{A. Baq/baqit}

Kazak Edebi Dili Sözlüğü'nde "Baqıt" (Mutluluk) kelimesi şöyle açıklanmıştır: Baqıt (Mutluluk, baht), isim. 1. baht, büyük sevinç, kıvanç. Örnek: Baqıt izdep nesine şarşağaımın, Qasımda jur eken goy ansaganım. O menin ön-samalım, jan-sonarım, Tamsanamın, tilinnen bal soramın! (Bahtımı arayarak boşuna yorulmuşum, Meğer İstediğim yanımdaymıs! Ey benim cereyanım, canımın arzusu, Imrenirim, dilinden bal emerim!). 2. İnsanın, bu hayatın neşesi ve hazmdan tatmin olma durumunu gösteren etik kavram. Baht çok anlamlı bir kelimedir. 1) Mutluluk, başına devlet kuşu konma, rızk; 2) sevinç, kıvanç, zevk alma, mutmain olma; 3) İyiliğe, ihsana kavuşma; 4) Hayata ayak uydurma, kemale erme, birey haline gelme. Eski Yunanistanlı filozoflar mutluluğun kuramsal manasını açıklamaya çalışmışlardır (Eflatun, Sokrates, Epikures) (Kazak Edebi Dilinin Sözlüğü 2006: 646).

Kazak Dilinin Açıklamalı Sözlügü̈’nde: Baht kelimesi “İnsanın istediğini elde ederek büyük sevinç duyması" şeklinde açıklanmıştır. Kazakçada baqıt kelimesi aşağıdaki kelimelerle birlikte kullanılarak deyimler oluşturur: baqıtka bölendi (Bahtına büründü) - mutlu oldu, eğlendi, tatmin oldu; Baqut qusu qondı (devlet kuşu kondu) - bahtına kavuştu, mutlu oldu, iyiliğe mazhar oldu; Baqıt quşă̆ında (Bahtın kucağında) - düşündüğünü elde ederek veya amacına ulaşarak sevinç yaşama; Baqıt quştı - istediğine kavuşarak mutlu oldu; Baqıt tanı attı (Bahtının şafağı söktü) - mutlu gün gelip çattı; Baqıtı jandı/açıldı (bahtı açıldı) - kader yüzüne güldü, şansı açıldı; Baqıtına qaray (Bahtına göre) -şansı yaver gitti, şansına göre; baqıtın sınadı (Bahtını denedi): şansını denedi; Baqıtı küydi (Bahtı yandı) - mutsuz duruma düştü, mutsuzlaştı; Baqıtın tüsürdi (Bahtını düşürdü) - Mutluluğunu kaybetti, şansını yitirdi; Baqıtın urladı (bahtını çaldı) - birini mutsuz etti (Kazak Dilinin Düşündürme Sözlü̈̆̈̈̈ 1977: 103).

Ayrıca Baqt (baht, mutluluk) kelimesiyle eş anlamlı olarak baq (baht), talay (talih) kelimeleri de kullanılmaktadır. Baq - baht, mutluluk, şans; băğ? arttı (bahtı arttı) - şan, şöhret sahibi oldu; băğ açıldı (bahtı açıldı) - mutlu oldu, băğ jandı (bahtı açıldı) - şansı yaver gitti; bă̆ı üstem boldı (bahtı üstün oldu) - devlet kuşu kondu, şöhreti arttı; bağına oray (bahtına göre) - şansı yaver gitti, baq qondı (baht kondu) - devlet kuşu kondu, mesut oldu; Baq qusu basına qondı (Başına devlet kuşu kondu) - mutluluğa, bolluğa kavuştu, mutlu oldu; bağın bazarda sinadı (bahtım pazarda denedi) - şansını denedi; baq sınastı (bahtlarını denedi) -yarış̧ı, şanslarını denedi; bağı kesildi (bahtı kesildi) - şanssız duruma düş̧ü, mutsuz oldu; bağın bayladı (bahtını bağladı) - Mutlu olmasına engel oldu, 
mutsuz etti; baq taydı (bahtı kaydı) - varlı̆̆ını, mülkünü kaybetti; baq talastırdı (bahtını yarıștırdl) - gıpta etti, haset etti kıskandl; baqkündes (hasetçi) birbirini çekemeyen, gipta ve hasetle dolu olan (insan) (Kazak Dilinin Düşündürme Sözlügü̈ 208:100).

Kazak dilbilimci İ. Kenesbayev'in Kazakçanın Deyimler Sözlüğ̈̈’nde Baqıt (baht) kelimesiyle birlikte kullanılan deyimlerin anlamı baq (baht, şans) kelimesiyle de seçenek olarak verilmiştir (Kenesbayev 1977: 87).

Baqıt (baht) kelimesinin Kazakçanm Etimolojik Sözlüğü'nde Arapçadan girmiş alıntı bir kelime olduğu belirtilmiştir. Ayrıca günümüz Kazakçasında bu kelimeyle eş anlamlı olarak kullanılan talay (talih, kader) kelimesi de mevcuttur. Adı geçen sözlükte talay kelimesinin etimolojisiyle ilgili yapılan açıklama şu şekildedir:

\section{B. Talay}

Talay (talih, şans). Kem be edi mende senen baq pen talay. Tilegenim menin de sol joldağı talayıf bolsın (M. Avezov) [Benim bahtım ve şansim seninkinden eksik miydi? Benim de istediğim, o yolda talihli

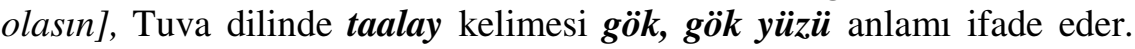
Kazakçadaki "Talayınnan kör" (kaderinden bil/ kaderine küs) ifadesi kanaatimizce eski şamanizmden kalma unsurdur. Eski çağlarda insanoğlu gökyüzünü Tanrı bilerek tapmıştır. Dolayısıyla günümüz Kazakçasında "Quday ursın" (Allah kahretsin) deyimiyle birlikte aynı anlamda "Kök soqsın" (Gök çarpsın) deyimi de kullanılmaktadır. Dolaysıyla "Bağınnan kör" (Şansından bil), "Mandayınnan kör" (alın yazından bil) deyimleri yerine bazen "Talayınnan kör" (talihinden bil/ talihine küs) deyimi de aynı anlamda kullanılır. Burada "Talayınnan kör" deyimi "gökten bil, Tanrı' dan bil" anlamı ifade eder.

Bu deyim ağız özelliğine de sahiptir. Çünkü bu deyim Kazakçanm tüm ağızlarında kullanılmaz. Doğu Türklerinin dilinde bu söz şamanizmle ilgili olarak kullanılmıştır (İskakov-Syzdıkova, vd 1966: 180).

\section{SONUÇ}

Sonuç olarak, Kazakça sözlüklerde bulunan baqıt (mutluluk) sözü, iyiliğe kavuşma, mesut bir şekilde bolluk içinde yaşama, şan ve şöhret sahibi olma, rızkı bol olma, söz sahibi olma, başarılara ulaşma vs. iyilikleri, güzel hal ve hasletlere insanoğlunun sahip olması gibi anlamlarla kaydedilmiş ve Kazakların dünya görüşlerinin oluşmasında müşterek bir kavram olarak ortaya çıkmıştır. 
İnsanoğlu hayatı boyunca mutlu yaşamasa bile, onun mutlu anları çok olabilir. Hatta olumsuz, küçük şeyler veya anlar, mutluluk olarak ifade edilebilir. Uzun yıllar yaşamış bir ihtiyar da henüz bir başarıya imza atamamış bir genç de kendini mutlu hissedebilir. Hayatta her şeyi elde etme ve başarma yanında elde edememe ve başarısız olma da vardı. Baht kelimesi ve bu kelimenin eş anlamlıları etrafında oluşan ve dile aksederek Kazak hayat görüşü ve anlayışının oluşmasına katkı sağlayan bu kavram, aynı zamanda insanları hayata ve birbirine bağlayan önemli bir husustur.

Sözün kısası, halk uzun yaşamasını, işinin iyiye doğru gitmesini, şansının yaver gitmesini, gamsız, kedersiz bolluk içinde yaşamayı, ister maddî ister manevî başarılarını, "baht, mutluluk" kavramıyla dile getirmeye çalışmıştır. Bu kavram, Kazakların dünya görüşlerinde huzurlu ve bereketli aile, gayret edip çabalama, nesil yetiştirme, güven içinde ve sağlıklı yaşama, mal ve mülkün emniyeti, mutlu yaşamın garantisi olmuştur. Bu nedenle "Baqıt" (mutluluk, baht) kelimesiyle birlikte deyim oluşturan çok sayıda kelimeler, milletin örf ve adetleri, dini, dili ve kültürüyle iç içe kaynaşarak, onun dünya görüşü ile düşüncesini ifade etmektedir. Dilimizdeki "baqıt" (mutluluk) kavramı Kazakların asırlarca hayat süzgecinden geçerek onları hayata, birbirine ve yaşadıkları coğrafyaya sımsıkı bağlayarak evrensel bir anlayışa dönüşmüştür.

\section{KAYNAKÇA}

BİJANOVA M (201), "Alemge Değen Dini Katınas Pen Ruhanilıktı Kalıptastyrudagı Bakıt Metafizikası", KR UGA Habarları, Kogamdık Gilımdar Seriasi. $N^{\circ}$, s. 67-71 .

ISKAKOV A.- SYZDIKOVA, R.- SARIBAEV, Ş. (1966) Kazak Tilinin Kıskaşa Etimologialık Sözdigi / kurastırgan. Almatı, Nauka, S.240 Kazak Adebi Tilinin Sözdügi (2006), On Bes Tomdık. II tom. A.-B. - A., Arış., s. 617649.

Kazak Tilinin Tusundirme Sözdigi (2008), (Jalpı Redaksıasın Baskargan T. Januzakov), - A., Dayk -Pres,. S.968.

KENESBAYEV t.( 1977), Kazak Tilinin Frazeologialık Sözdigi, - A., Gılım, s.712.

MASLOVA V.A.(2004), Kognitivnaya Lingvistika - Minsk: Tetra Sist., s. 55.

ORAZALIYEVA E. (2007), Kognitivtik Lingvistika: Kalıptasuı Men Damuı Gilumi Monografía - A., Arıs, 2007. S. 312.

VORKAÇEV S.G. (2006), "Lingvokultumaya Konseptologia: Stanovlenie i Perspektivı", Voprosı Yasıkoznania, M.: Nauka, s.20- 36. 